\title{
Climate change and global child health: what can paediatricians do?
}

\author{
Zulfiqar Ahmed Bhutta, ${ }^{1,2}$ Ashley Aimone, ${ }^{3}$ Saeed Akhtar ${ }^{4}$
}

A little over a decade ago, the Lancet Climate Commission concluded that anthropogenic climate change threatens to undermine the past 50 years of gains in public health and, conversely, that a comprehensive response to climate change could be 'the greatest global health opportunity of the 21 st century'. ${ }^{1}$ In a recent review, experts quantified the impact of climate change on health and estimated that heatwaves between 2000 and 2016 had resulted in 5.3\% lower outdoor manual productivity and that economic losses from climate change related events in 2016 alone totalled almost US\$129 billion. ${ }^{2}$

Historically, major excess mortality peaks have been related to extreme weather events, such as the Bangladesh cyclone of 1991, Venezuela floods and mudslides of 1999 and Myanmar cyclone of 2008. These three extreme weather events alone accounted for more than 300000 deaths. $^{2}$ It is estimated that Hurricane Maria affecting Puerto Rico in 2017 was associated with excess mortality with estimates ranging between 2700 and 4600 deaths. $^{34}$

In addition to direct effects and increased risks of climate change associated disasters such as drought or floods, global climate change has been associated with major changes in infectious diseases risks. The annual numbers of cases of dengue fever have doubled every decade since 1990 , with 58.4 million apparent cases in 2013, accounting for more than 10000 deaths. ${ }^{5}$ Other infectious diseases, such as yellow fever, chikungunya, Mayaro and Zika viruses, are probably similarly responsive to climate change. ${ }^{2}$

Children pay a disproportionate price for climate change, with some estimates

\footnotetext{
${ }^{1}$ Centre for Global Child Health, Toronto, Ontario, Canada

${ }^{2}$ Center of Excellence in Women and Child Health, The Aga Khan University, Karachi, Pakistan

${ }^{3}$ Centre for Global Child Health, The Hospital for Sick Children, Toronto, Ontario, Canada

${ }^{4}$ Institute of Food Science \& Nutrition, Bahauddin Zakariya University, Multan, Pakistan
}

Correspondence to Professor Zulfigar Ahmed Bhutta Robert Harding Chair in Global Child Health \& Policy, Centre for Global Child Health, The Hospital for Sick Children, Toronto, ON M5G 0A4, Canada ; zulfiqar.bhutta@sickkids.ca suggesting up to $88 \%$ of the burden of disease related to it. ${ }^{6}$ Such excess risks are related to a combination of physiological vulnerability, especially among young children, as well as risk of exposure. In a study of nearly 500000 deaths in the Catalonia region of Spain during the warm seasons of 1983-2006, Basagaña et $a l^{7}$ evaluated the association between the occurrence of extremely hot days (days with maximum temperature above the 95th percentile) and mortality. They documented 50\% excess mortality among infants in the perinatal period during these extremely hot days (relative risk of death from conditions originating in the perinatal period was 1.53 (95\% CI 1.16 to 2.02).

The risk-magnifying effect of climate change has a large impact on food systems, which are already facing increased pressure from the demands of a growing global population, increased urbanisation and loss of biodiversity. Food security will be increasingly threatened, as climate change influences both the quality and quantity of food we are able to produce. ${ }^{8}$ For example, global wheat production could reduce by $6 \%$ for each $1^{\circ} \mathrm{C}$ rise in temperature. ${ }^{9}$ Lloyd et al developed a statistical model to project moderate and severe stunting in children aged $<5$ years at the national level in 2030 in 44 countries under low and high climate change scenarios, controlling for economic factors. ${ }^{10}$ Their estimates indicated that climate change-attributable stunting ranged from 570000 under the best-case scenario to $>1$ million under the poverty/ high climate change scenario. ${ }^{10}$ Natural disasters also increase these mortality risks through direct effects and population displacement. Some 160 million children live in extreme drought zones, and an additional 500 million children live in areas with extreme flood risks. ${ }^{11}$ The WHO projects that there could be additional 77 000-131 000 deaths among children under 5 years of age in 2030 if no mitigation strategies are put in place. ${ }^{12}$

Notwithstanding denial by some, there is remarkable consensus among academia and professionals that climate change is both real and an existential threat for the planet. While there are remarkable examples of adaptation and resilience, effective change will require concerted and extensive multisectoral efforts at scale, as defined by the Paris Climate Change Treaty. ${ }^{13}$

What role can paediatricians and paediatric associations play in this regard? There is widespread thinking that the mitigation strategies for climate change are an issue for governments and multilateral organisations. Others have focused on personal and institutional actions and leading by example through collective efforts to reduce energy consumption and waste within home and work environments. ${ }^{14} 15$ These are actions that paediatricians can promote in their homes, clinics and hospitals. There is a clear need to do more and lead by example. Paediatricians have a special responsibility for children and must become engaged in strategies to address climate change, the environmental sustainability of health systems and the resilience of population health to environmental change. ${ }^{16}$ Concerted efforts in this regards must include extensive continuing medical education activities by professional bodies and paediatric associations to include climate change. For example, climate change-related information and learning materials must be included within global child health teaching modules and open-access courses as well as residency training programmes. National, regional and global paediatric associations must include educational activities on climate change and health within their conferences and programmes for educating delegates. These must be organised in the most eco-friendly manner with a minimal carbon footprint.

Importantly, given the disproportionate effects of climate change on children, paediatricians and paediatric associations must become strong advocates to exert pressure on governments, corporations and private sector institutions to adopt mitigation strategies for climate change. Additionally, appropriate and robust research should be facilitated to help children and families. ${ }^{17}$ To illustrate, future research should also determine if the burden of climate change on children is gender, age and socioeconomic status specific and if inequities exist. Healthcare professionals may be well positioned as health educators (and trusted sources of information) to raise awareness about climate change and health among their patients and in their communities. These advocacy efforts and actions can begin locally but rapidly extend to citywide actions, regions and indeed nationally. Developing and monitoring estimates for the contribution of climate change and environmental factors to child health and mortality must move from the pages of scientific journals ${ }^{18}$ to mainstream debates and action. 
Amid the doomsday scenarios that rapid climate change foretells, there is room for optimism that collective action can bring about change. With the sustainable development goals that have been signed into a global compact by 193 countries of the world, ${ }^{19}$ there are unprecedented opportunities to make real and lasting strides in towards better health and well-being for generations to come (starting with our children of today). Paediatricians can play a pivotal role in translating research to practice and leading a global movement that can address many determinants of planetary health and health inequities within a generation.

Contributors All authors contributed to the article. ZAB wrote the first draft and is the guarantor.

Funding The authors have not declared a specific grant for this research from any funding agency in the public, commercial or not-for-profit sectors.

Competing interests None declared.

\section{Patient consent for publication Not} required.

Provenance and peer review Commissioned; internally peer reviewed.

(c) Author(s) (or their employer(s)) 2019. No commercial re-use. See rights and permissions. Published by BMJ.

Check for updates
To cite Bhutta ZA, Aimone A, Akhtar S. Arch Dis Child 2019;104:417-418.

Received 18 February 2019

Revised 5 March 2019

Accepted 6 March 2019

Published Online First 16 March 2019

Arch Dis Child 2019;104:417-418.

doi:10.1136/archdischild-2018-316694

\section{REFERENCES}

1 Costello A, Abbas M, Allen A, et al. Managing the health effects of climate change: Lancet and University College London Institute for Global Health Commission. Lancet 2009;373:1693-733.

2 Watts N, Amann M, Ayeb-Karlsson S, et al. The Lancet Countdown on health and climate change: from 25 years of inaction to a global transformation for public health. Lancet 2018:391:581-630.

3 Santos-Burgoa C, Sandberg J, Suárez E, et al. Differential and persistent risk of excess mortality from Hurricane Maria in Puerto Rico: a time-series analysis. Lancet Planet Health 2018;2:e478-e488.

4 Kishore N, Marqués D, Mahmud A, et al. Mortality in Puerto Rico after Hurricane Maria. N Engl J Med 2018:379162-70.

5 Stanaway JD, Shepard DS, Undurraga EA, et al. The globa burden of dengue: an analysis from the Global Burden of Disease Study 2013. Lancet Infect Dis 2016;16:712-23.

6 Philipsborn RP, Chan K. Climate Change and Global Child Health. Pediatrics 2018;141:e20173774.

7 Basagaña X, Sartini C, Barrera-Gómez J, et al. Heat waves and cause-specific mortality at all ages. Epidemiology 2011;22:765-72.

8 Myers SS, Smith MR, Guth S, et al. Climate change and global food systems: potential impacts on food security and undernutrition. Annu Rev Public Health 2017;38:259-77.
9 Asseng S, Ewert F, Martre P, et al. Rising temperatures reduce global wheat production. Nat Clim Chang 2015;5:143-7.

10 Lloyd SJ, Kovats RS, Chalabi Z. Climate change, crop yields, and undernutrition: development of a model to quantify the impact of climate scenarios on child undernutrition. Environ Health Perspect 2011:119:1817-23.

11 United Nations Children's Fund. Unless we act now: the impact of climate change on children. New York, NY: UNICEF, 2015

12 Lloyd S, Kovats $S$, Chalabi Z. et al Undernutrition. In: Hales S, Kovats S, Lloyd S, Campbell-Lendrum D, . eds. Quantitative Risk Assessment of the effects of climate change on select causes of death, 2030s and 2050s. Geneva, Switzerland: World Health Organization, 2014:69-94.

13 Bhore SJ. Paris agreement on climate change: a booster to enable sustainable global development and beyond. Int J Environ Res Public Health 2016;13:pii: E1134.

14 Isaacs D. Climate change: The moral role of paediatricians. J Paediatr Child Health 2015; 51:843-4.

15 Seal A, Vasudevan C. Climate change and child health. Arch Dis Child 2011;96:1162-6.

16 Whitmee S, Haines A, Beyrer C, et al. Safeguarding human health in the Anthropocene epoch: report of The Rockefeller Foundation-Lancet Commission on planetary health. Lancet 2015;386:1973-2028.

$17 \mathrm{Xu}$ Z, Sheffield PE, Hu W, et al. Climate change and children's health--a call for research on what works to protect children. Int J Environ Res Public Health 2012;9:3298-316.

18 Heft-Neal S, Burney J, Bendavid E, et al. Robust relationship between air quality and infant mortality in Africa. Nature 2018;559:254-8.

19 United Nations. The sustainable development agenda; 17 goals to transform our world. https://www.un.org/ sustainabledevelopment/development-agenda/. 